\title{
Comparison of the Hemodynamic Effects of the Induction Agents Ketamine, Etomidate and Sevoflurane Using the Model of Electrical Velocimetry Based Cardiac Output Monitoring in Pediatric Cardiac Surgical Patients
}

\author{
Suruchi Hasija ${ }^{*}$, Sandeep Chauhan1, Neeti Makhija1, Sarvesh Pal Singh', Sanjay Kumar1, \\ Arin Choudhury', Sachin Talwar ${ }^{2}$, Usha Kiran'1 \\ ${ }^{1}$ Department of Cardiac Anaesthesiolgy, All India Institute of Medical Sciences, New Delhi, India \\ ${ }^{2}$ Department of Cardiothoracic and Vascular Surgery, All India Institute of Medical Sciences, New Delhi, India \\ Email: suruchi hasija@hotmail.com
}

Received 4 August 2014; revised 4 September 2014; accepted 30 September 2014

Copyright @ 2014 by authors and Scientific Research Publishing Inc.

This work is licensed under the Creative Commons Attribution International License (CC BY).

http://creativecommons.org/licenses/by/4.0/

(c) (i)

\section{Abstract}

Objective: To compare the haemodynamic effects of the induction agents ketamine, etomidate and sevoflurane using the model of electrical velocimetry based cardiac output monitoring in paediatric cardiac surgical patients. Design: Prospective randomized study. Setting: Tertiary care hospital. Participants: 60 children $<2$ years age undergoing cardiac surgery. Interventions: The patients were randomized into 3 equal groups to receive $1.5-2.5 \mathrm{mg} / \mathrm{kg}$ iv ketamine (group $\mathrm{K}$ ), $0.2-0.3 \mathrm{mg} / \mathrm{kg}$ iv etomidate (group E) or upto 8\% sevoflurane (group S) as the induction agent. Hemodynamic parameters were noted before and after induction of anaesthesia utilizing a noninvasive cardiac monitor based on the model of electrical velocimetry. Measurements and Main Results: The demographic characteristics of the patients were similar in the three groups. The HR decreased in all groups, least in group $\mathrm{E}(P \leq 0.01)$ but the MAP decreased only in group $S(P \leq 0.001)$. In group $S$, the stroke volume improved from $9 \pm 3.2 \mathrm{ml}$ to $10 \pm 3.2 \mathrm{ml}(P \leq 0.05)$ and the stroke volume variation decreased from $25 \% \pm 6.4 \%$ to $13 \% \pm 6.2 \%(P \leq 0.001)$. The stroke index and systemic arterial saturation improved in all groups $(P \leq 0.01)$. The cardiac index and index of contractility were unchanged. The transthoracic fluid content reduced in groups $E$ and $S$, but did not change in group $K(P \leq 0.05)$. Conclusions: Etomidate appeared to provide the most stable conditions for induction

${ }^{*}$ Corresponding author.

How to cite this paper: Hasija, S., et al. (2014) Comparison of the Hemodynamic Effects of the Induction Agents Ketamine, Etomidate and Sevoflurane Using the Model of Electrical Velocimetry Based Cardiac Output Monitoring in Pediatric Cardiac Surgical Patients. World Journal of Cardiovascular Surgery, 4, 167-175. http://dx.doi.org/10.4236/wjcs.2014.410024 
of anesthesia in children undergoing cardiac surgery, followed by ketamine and sevoflurane.

\title{
Keywords
}

\author{
Anesthesia Induction Agents, Electrical Velocimetry, Noninvasive Hemodynamic Monitoring, \\ Pediatric Cardiac Surgery
}

\section{Introduction}

Children with congenital heart disease (CHD) undergoing cardiac surgery are in a precarious hemodynamic state and the choice of the anesthetic induction agent seems important in such a situation. The doses of anesthetic agents otherwise tolerated by patients with normal cardiovascular anatomy might lead to hemodynamic collapse in children with CHD. There exist a few studies in the literature on the hemodynamic effects of anesthetic induction agents in children with CHD [1]-[10]. No specific anesthetic induction technique has been advocated for children with CHD. A number of factors influence the choice of the anesthetic technique including heart rate (HR), rhythm, myocardial contractility, shunting, outflow tract obstruction, ventricular dilation and hypertrophy, and pulmonary hypertension in the pediatric cardiac surgical patient. The anesthetic goals remain to maintain normal HR, sinus rhythm, maintain myocardial contractility, minimize pulmonary or systemic overcirculation across shunt lesion and lower pulmonary vascular resistance (PVR).

Pediatric cardiac surgical patients require intensive cardiac monitoring. The capability to continuously monitor cardiac output (CO) non-invasively is invaluable in the management of children with hemodynamic compromise who require frequent adjustments in supportive care, volume administration and titration of vasoactive agents. Hitherto, it was only possible to do so with the dye dilution, thermodilution, methods based on Fick principle, pulse contour techniques and echocardiography. These techniques are either invasive or provide information intermittently. In addition, insertion of the pulmonary artery catheter in children is technically more difficult and carries more complications than in adults [11]. But with the advent of electrical velocimetry (EV), $\mathrm{CO}$ and its derived parameters can be obtained noninvasively and continuously even in the pediatric population [12]-[15].

The aim of the present study was to compare the hemodynamic effects of the induction agents etomidate, ketamine and sevoflurane using the model of EV based CO monitoring in pediatric cardiac surgical patients.

\section{Material and Methods}

Sixty pediatric patients under 2 years of age with CHD undergoing cardiac surgery were studied prospectively after obtaining ethical approval from the Institutional Review Board and written informed consent from the parents of participating patients. The exclusion criteria were emergency surgery, previous cardiac surgery, age more than 2 years, patient on mechanical ventilaton or vasoactive medication, and presence of arrhythmias or pacemaker. Based on the anesthetic induction agent to be used, the patients were divided into three groups of 20 each using computer generated random number table: group E (etomidate), group K (ketamine) and group S (sevoflurane). Preoperative work up included haematological investigations (complete blood count, renal function tests, serum electrolytes), chest radiograph, electrocardiogram and transthorcic echocardiography. Patients were required to fast for 2 hours for clear fluids, 4 hours for breast or formula milk and 6 hours for solids. All cardiac medications were continued till the morning of surgery. Patients weighing more than $5 \mathrm{~kg}$ were premedicated with syrup phenargan $0.5 \mathrm{mg} / \mathrm{kg}$ orally 30 minutes before induction of general anesthesia. In the operating room, monitoring was established with 5-lead electrocardiography (ECG), pulse oximetry, noninvasive blood pressure, bispectral index monitor (BIS ${ }^{\mathrm{TM}}$ monitoring system, Aspect Medical Systems Inc., Newton, MA, USA) and noninvasive CO monitor (ICON ${ }^{\circledR}$ Osypka Medical GmBH, Berlin, Germany). Baseline readings of the following hemodynamic parameters were taken: HR, systolic/diastolic/mean blood pressure, stroke volume (SV), stroke index (SI), CO, cardiac index (CI), index of contractility (ICON), variation of the index of contractility (VIC), stroke volume variation (SVV), transthoracic fluid content (TFC), systemic arterial saturation $\left(\mathrm{SaO}_{2}\right)$, arterial oxygen content $\left(\mathrm{CaO}_{2}\right)$, oxygen delivery $\left(\mathrm{DO}_{2}\right)$ and oxygen delivery index $\left(\mathrm{DO}_{2} \mathrm{I}\right)$. A 22/24 gauge i.v. cannula was inserted in the groups $\mathrm{E}$ and $\mathrm{K}$. Anesthesia was induced with either $0.2-0.3 \mathrm{mg} / \mathrm{kg}$ etomidate (i.v.) (group E), 
1.5 - $2.5 \mathrm{mg} / \mathrm{kg}$ ketamine (i.v.) (group K) or sevoflurane (upto 8\%) (group S) ensuring loss of eyelash reflex and BIS value $<50$. Ventilation was assisted with oxygen:air mixture (50:50). The readings of various hemodynamic parameters were noted again. Thereafter, $2 \mu \mathrm{g} / \mathrm{kg}$ fentanyl (i.v.) and $1.0 \mathrm{mg} / \mathrm{kg}$ rocuronium (i.v.) were administered. After tracheal intubation, an arterial cannula and a triple lumen central venous catheter were inserted. Anesthesia was maintained with fentanyl, midazolam, vecuronium and sevoflurane. The conduct of anesthesia, surgery and cardiopulmonary bypass was according to standard institutional protocol.

The principles and method of estimation of CO using EV by ICON ${ }^{\circledR}$ are as follows: ECG electrodes are placed one each over the forehead, left side of the neck, left mid-axillary line at the level of xiphoid process and left thigh. A small alternate electrical current flows through the thorax from the outer ECG electrodes and the resulting voltage is measured by the inner electrodes. The ratio of applied current and measured voltage equals the conductivity. ICON ${ }^{\circledR}$ determines beat-to-beat parameters characterizing the performance of the heart including SV and CO, based on the principle of EV. The model ascribes the changes in thoracic bioimpedance to the change in orientation of the erythrocytes in the aorta. As red blood cells are aligned during systole and misaligned during diastole, the conductivity is higher and voltage lower during systole, whereas the conductivity is lower and voltage higher during diastole. The mean velocity index empirically derived from a peak amplitude measurement is assumed to be an index of peak aortic acceleration of blood flow. EV by ICON uses an algorithm which estimates SV in millilitres based on the mean velocity index, the flow time and the body mass. SV multiplied by HR yields $\mathrm{CO}$ in millilitres per minute. The other calculations used are:

$$
\begin{gathered}
\text { ICON }(\text { Index of Contractility })=\frac{\mathrm{dZ}(\mathrm{t}) / \mathrm{dt}}{\mathrm{Z}_{0}} \text {, where } \mathrm{Z} \text { is the impedance } \\
\mathrm{VIC}(\text { Variation of the Index of Contractility })=\frac{\text { standard deviation ICON }}{\text { mean ICON }} \times 100 \\
\operatorname{SVV}(\text { Stroke Volume Variation })=\frac{\text { standard deviation SV }}{\text { mean SV }} \times 100 .
\end{gathered}
$$

\section{Statistical Analysis}

Statistical package SPSS 15.0 for windows (SPSS Inc, Chicago, IL) was used for statistical analysis. The power of the study was $90 \%$. All values were expressed as frequency $(n)$ or mean \pm 1 standard deviation. Qualitative data was analyzed by Chi-square test. Quantitative data was analyzed by paired t-test. All changes in hemodynamic parameters before and after induction of anesthesia were analyzed with ANOVA. A $P$ value of $\leq 0.05$ was considered significant.

\section{Results}

A total of 60 patients randomized into 3 equal groups were included in the study. The mean age of children in the groups $\mathrm{K}, \mathrm{E}$ and $\mathrm{S}$ was $8.1,10.4$ and 13.7 months, respectively $(P=0.08)$. The mean weight of children in the groups $\mathrm{K}, \mathrm{E}$ and $\mathrm{S}$ was $5.1,5.9$ and $6.6 \mathrm{~kg}$, respectively $(P=0.12)$. The height, body surface area and gender distribution was similar, with boys outnumbering girls. The children were on identical medications preoperatively, those with increased pulmonary blood flow received furosemide and digoxin, and those with decreased pulmonary blood flow received propranolol (Table 1).

The majority of children had cyanotic CHD (70\%) with increased pulmonary blood flow (83.3\%) (Table 2). The most frequent diagnosis was transposition of great arteries followed by ventricular septal defect, and double outlet right ventricle (Table 3 ).

All the baseline hemodynamic variables were comparable in the three groups (Table 4). The baseline HR and mean arterial pressure (MAP) were similar in all groups: $159 \mathrm{bpm}$ and $76 \mathrm{mmHg}$ (group K), $154 \mathrm{bpm}$ and 75 $\mathrm{mmHg}$ (group E), $161 \mathrm{bpm}$ and $80 \mathrm{mmHg}$ (group S). The HR decreased in all groups, least in group $\mathrm{E}(P \leq 0.01)$ but the MAP decreased only in group $S(P \leq 0.001)$ (Figure 1 and Figure 2). The decrease in MAP from $80 \pm$ $16.3 \mathrm{mmHg}$ to $64 \pm 15.1 \mathrm{mmHg}$ in group S was greater than $20 \%$ from baseline. In group S, the SV improved from $9 \pm 3.2 \mathrm{ml}$ to $10 \pm 3.2 \mathrm{ml}(P \leq 0.05)$ and the SVV decreased from $25 \% \pm 6.4 \%$ to $13 \% \pm 6.2 \%(P \leq 0.001)$ (Figure 3). The SI and $\mathrm{SaO}_{2}$ improved in all groups $(P \leq 0.01)$ (Figure 4). The $\mathrm{CI}$ and ICON were unchanged (Figure 5 and Figure 6). VIC remained unchanged in group E $(27 \% \pm 12.1 \%$ to $26 \% \pm 9.4 \%$ after in- 
Table 1. Demographic characteristics.

\begin{tabular}{ccccc}
\hline Variable & GROUP K $(\boldsymbol{n}=\mathbf{2 0})$ & GROUP E $(\boldsymbol{n}=\mathbf{2 0})$ & GROUP S $(\boldsymbol{n}=\mathbf{2 0})$ & P value \\
\hline Age (months) (mean \pm S.D.) & $8.1 \pm 7.07$ & $10.4 \pm 8.22$ & $13.7 \pm 8.08$ & 0.08 \\
Sex (M/F) $(n)$ & $16 / 4$ & $16 / 4$ & $11 / 9$ & 0.13 \\
Height (cm) (mean \pm S.D.) & $64.0 \pm 14.28$ & $67.7 \pm 11.68$ & $70.1 \pm 9.45$ & 0.28 \\
Weight $(\mathrm{kg})$ (mean \pm S.D.) & $5.1 \pm 2.33$ & $5.9 \pm 2.44$ & $6.6 \pm 2.25$ & 0.12 \\
BSA (m ${ }^{2}$ ) (mean \pm S.D.) & $0.29 \pm 0.096$ & $0.32 \pm 0.109$ & $0.35 \pm 0.082$ & 0.13 \\
Preoperative treatment: & & & & 0.30 \\
Propranolol $(n)$ & 5 & 2 & 19 & 0.21 \\
Furosemide $(n)$ & 14 & 16 & 13 & 0.41 \\
Digoxin $(n)$ & 8 & 11 & 1 & 0.28 \\
Antibiotics $(n)$ & 4 & 5 & & \\
\hline
\end{tabular}

BSA: Body surface area.

Table 2. Characteristics of congenital heart disease.

\begin{tabular}{|c|c|c|c|c|}
\hline Variable & GROUP K $(n=20)$ & GROUP E $(n=20)$ & GROUP S $(n=20)$ & $P$ value \\
\hline Acyanotic/Cyanotic (A/C) (n) & $5 / 15$ & $7 / 13$ & $6 / 14$ & 0.12 \\
\hline Qp/Qs > $1(n)$ & $14 / 6$ & $17 / 3$ & $19 / 1$ & 0.13 \\
\hline Left ventricular dysfunction (n) & 1 & 1 & 1 & 0.50 \\
\hline Right ventricular dysfunction ( $n$ ) & 3 & 1 & 1 & 0.15 \\
\hline
\end{tabular}

Qp/Qs: pulmonary blood flow/systemic blood flow.

Table 3. Diagnosis.

\section{Diagnosis \\ Aortopulmonary window}

Atrial septal defect + Coarctation of aorta

Atrial septal defect + Ventricular septal defect

Atrial septal defect + Ventricular septal defect + Patent ductus arteriosus

Double outlet right ventricle

d-Transposition of great arteries

Endocardial cushion defect

Partial anomalous pulmonary venous drainage

Patent ductus arteriosus

Total anomalous pulmonary venous drainage

Tetralogy of Fallot

Tricuspid atresia

Ventricular septal defect $\mathbf{n}=\mathbf{6 0}$

1

1

2

1

8

22

1

1

1

3

5

4

10

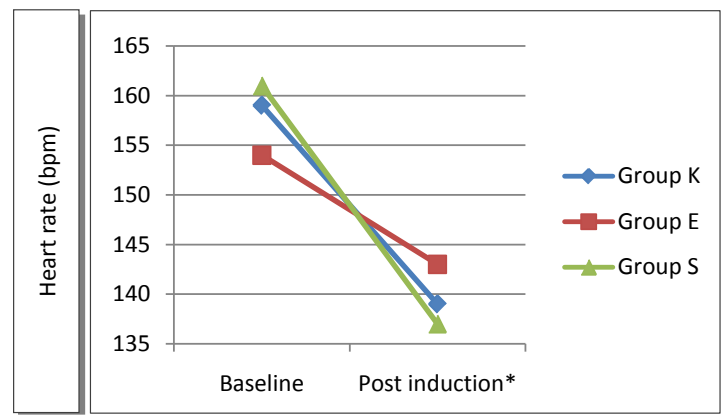

${ }^{*} P \leq 0.01$ for all three groups.

Figure 1. Change in heart rate after induction. 


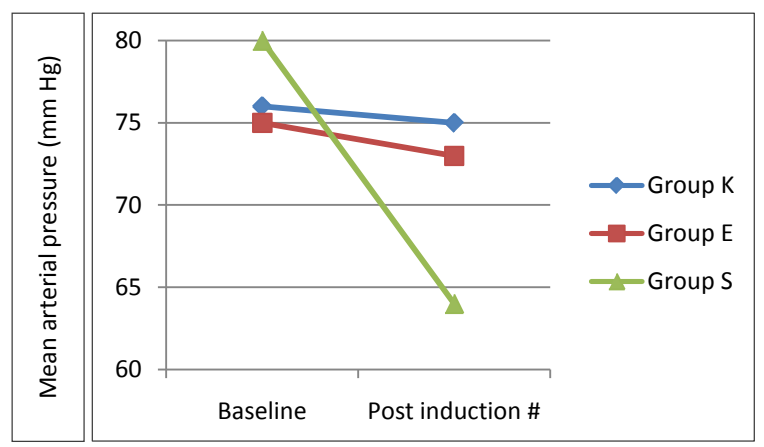

${ }^{\#} P \leq 0.001$ for group $\mathrm{S}$.

Figure 2. Change in mean arterial pressure after induction.

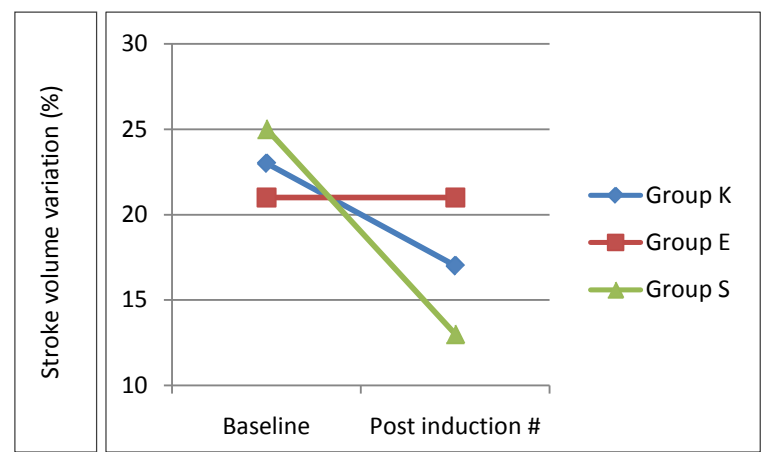

${ }^{\#} P \leq 0.001$ for group $\mathrm{S}$.

Figure 3. Change in stroke volume variation after induction.

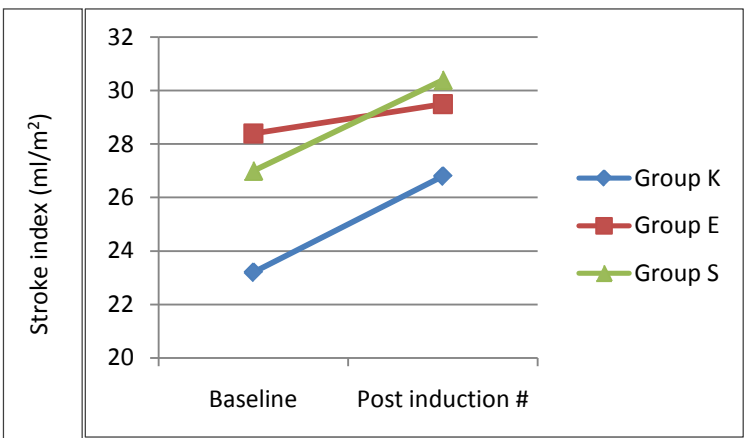

${ }^{\#} P \leq 0.001$ for all three groups.

Figure 4. Change in stroke index after induction.

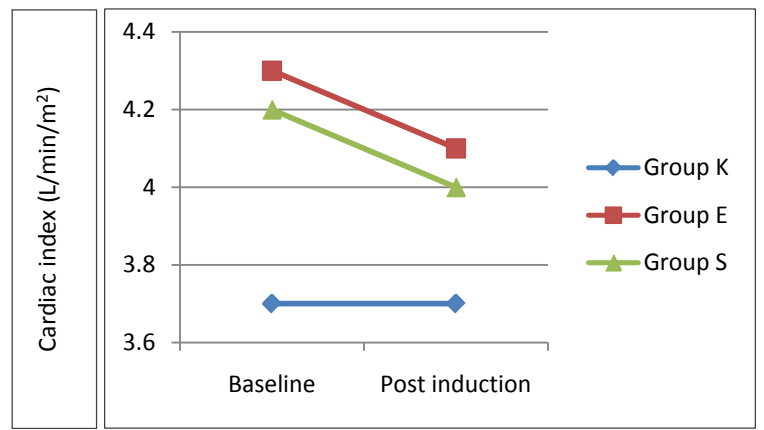

Figure 5. Change in cardiac index after induction. 


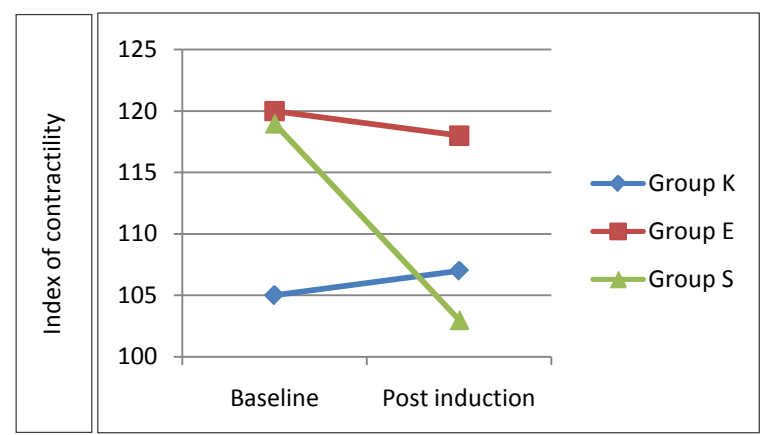

Figure 6. Change in index of contractility after induction.

Table 4. Comparison of haemodynamic variables before and after induction of anaesthesia.

\begin{tabular}{|c|c|c|c|c|c|c|}
\hline \multirow{2}{*}{$\begin{array}{c}\text { Variable } \\
(\text { mean } \pm \text { SD) }\end{array}$} & \multicolumn{2}{|c|}{ GROUP K $(n=20)$} & \multicolumn{2}{|c|}{ GROUP E $(n=20)$} & \multicolumn{2}{|c|}{ GROUP S $(n=20)$} \\
\hline & Before & After & Before & After & Before & After \\
\hline HR (bpm) & $159 \pm 28.0$ & $139 \pm 20.5^{c}$ & $154 \pm 26.0$ & $143 \pm 23.7^{b}$ & $161 \pm 14.0$ & $137 \pm 16.0^{c}$ \\
\hline Systolic BP (mmHg) & $100 \pm 18.6$ & $105 \pm 15.5$ & $106 \pm 15.0$ & $101 \pm 15.0$ & $103 \pm 18.7$ & $95 \pm 15.6^{\mathrm{a}}$ \\
\hline Diastolic BP (mmHg) & $68 \pm 17.0$ & $66 \pm 13.6$ & $67 \pm 13.3$ & $64 \pm 11.7$ & $72 \pm 16.6$ & $55 \pm 15.6^{c}$ \\
\hline Mean BP (mmHg) & $76 \pm 16.8$ & $75 \pm 13.0$ & $75 \pm 12.3$ & $73 \pm 11.2$ & $80 \pm 16.3$ & $64 \pm 15.1^{c}$ \\
\hline $\mathrm{SV}(\mathrm{ml})$ & $7 \pm 3.6$ & $8 \pm 4.7$ & $10 \pm 5.7$ & $10 \pm 5.1$ & $9 \pm 3.2$ & $10 \pm 3.2^{\mathrm{a}}$ \\
\hline $\mathrm{SI}\left(\mathrm{ml} / \mathrm{m}^{2}\right)$ & $23.2 \pm 6.37$ & $26.8 \pm 6.32^{c}$ & $28.4 \pm 8.49$ & $29.5 \pm 7.37^{\mathrm{c}}$ & $27.0 \pm 4.36$ & $30.4 \pm 5.6^{c}$ \\
\hline $\mathrm{CO}(\mathrm{L} / \mathrm{min})$ & $1.1 \pm 0.40$ & $1.1 \pm 0.52$ & $1.4 \pm 0.60$ & $1.3 \pm 0.50$ & $1.5 \pm 0.49$ & $1.4 \pm 0.43$ \\
\hline $\mathrm{CI}\left(\mathrm{L} / \mathrm{min} / \mathrm{m}^{2}\right)$ & $3.7 \pm 1.36$ & $3.7 \pm 1.03$ & $4.3 \pm 0.91$ & $4.1 \pm 0.95$ & $4.2 \pm 0.57$ & $4.0 \pm 0.70$ \\
\hline ICON & $105 \pm 26.7$ & $107 \pm 34.4$ & $120 \pm 41.8$ & $118 \pm 37.1$ & $119 \pm 23.2$ & $103 \pm 25.4$ \\
\hline VIC (\%) & $32 \pm 10.8$ & $22 \pm 12.0^{b}$ & $27 \pm 12.1$ & $26 \pm 9.4$ & $30 \pm 9.0$ & $17 \pm 10.0^{c}$ \\
\hline SVV (\%) & $23 \pm 7.8$ & $17 \pm 7.0$ & $21 \pm 8.1$ & $21 \pm 7.8$ & $25 \pm 6.4$ & $13 \pm 6.2^{c}$ \\
\hline $\operatorname{TFC}\left(\Omega^{-1}\right)$ & $20 \pm 3.4$ & $20 \pm 3.7$ & $22 \pm 3.1$ & $21 \pm 3.4^{\mathrm{a}}$ & $22 \pm 4.5$ & $21 \pm 4.6^{\mathrm{a}}$ \\
\hline $\mathrm{SaO}_{2}(\%)$ & $79 \pm 16.8$ & $85 \pm 14.8^{b}$ & $86 \pm 12.7$ & $91 \pm 11.4^{c}$ & $87 \pm 17.9$ & $92 \pm 16.8^{c}$ \\
\hline $\mathrm{CaO}_{2}(\mathrm{ml})$ & $15 \pm 3.2$ & $16 \pm 2.9$ & $15 \pm 1.7$ & $16 \pm 2.1^{b}$ & $14 \pm 2.6$ & $14 \pm 2.6$ \\
\hline $\mathrm{DO}_{2}(\mathrm{~mL})$ & $156 \pm 70.6$ & $167 \pm 81.9$ & $209 \pm 100.1$ & $212 \pm 89.7$ & $202 \pm 84.4$ & $205 \pm 80.0$ \\
\hline $\mathrm{DO}_{2} \mathrm{I}\left(\mathrm{ml} / \mathrm{m}^{2}\right)$ & $547.9 \pm 212.95$ & $559.6 \pm 130.60$ & $630.9 \pm 158.93$ & $643.5 \pm 147.23$ & $575.6 \pm 147.26$ & $580.7 \pm 142.27$ \\
\hline
\end{tabular}

${ }^{\mathrm{a}} \mathrm{P} \leq 0.05,{ }^{\mathrm{b}} \mathrm{P} \leq 0.01,{ }^{\mathrm{c}} \mathrm{P} \leq 0.001$ for within group comparisons. $P$ insignificant for intergroup comparisons at baseline. $\mathrm{BP}$ : blood pressure, CaO $\mathrm{O}_{2}$ : arterial oxygen content, $\mathrm{CI}$ : cardiac index, CO: cardiac output, $\mathrm{DO}_{2}$ : oxygen delivery, $\mathrm{DO}_{2} \mathrm{I}$ : oxygen delivery index, HR: heart rate, ICON: index of contractility, $\mathrm{SaO}_{2}$ : arterial oxygen saturation, SI: stroke index, SV: stroke volume, SVV: stroke volume variation, TFC: transthoracic fluid content, VIC: variation of index of contractility.

duction), unlike group $\mathrm{K}(32 \% \pm 10.8 \%$ to $22 \% \pm 12.0 \%, P \leq 0.01)$ and group $\mathrm{S}(30 \% \pm 9.0 \%$ to $17 \% \pm 10.0 \%$, $P \leq 0.001)$. The TFC reduced in groups $\mathrm{E}$ and $\mathrm{S}$, but did not change in group $\mathrm{K}(P \leq 0.05)$. There was an increase in the $\mathrm{CaO}_{2}$ value in group $\mathrm{E}(P \leq 0.01)$, whereas $\mathrm{DO}_{2}$ was unchanged in all groups.

No untoward event occurred during induction of anesthesia in the present series of patients.

\section{Discussion}

There exist a few studies in the literature on the hemodynamic effects of anesthetic induction agents in children with CHD [1]-[10]. Ketamine (2 mg/kg i.v.) has been shown to cause minor increases in HR, pulmonary artery pressure (PAP) and PVR, whereas no significant changes in MAP, systemic vascular resistance (SVR), shunting, or arterial oxygen or carbon dioxide tensions in children with CHD undergoing cardiac catheterization [1]. Ketamine infusion (50 - $75 \mu \mathrm{g} / \mathrm{kg} / \mathrm{min}$ ) increased MAP but did not alter PAP, SVR or PVR in children with CHD during cardiac catheterization [2]. Ketamine sedation in acyanotic children undergoing cardiac catheterization was found to increase oxygen consumption, HR, CO, PAP and PVR [3]. In a study on the comparison of 
sevoflurane and ketamine for anesthetic induction in children with $\mathrm{CHD}, \mathrm{HR}$ and $\mathrm{SaO}_{2}$ were similar, though MAP was lower in the group that received sevoflurane. Ketamine appeared to be a better alternative for induction in such patients as it permitted preservation of hemodynamic stability with minimal side effects [4]. A study determining the combined effect of ketamine $(1 \mathrm{mg} / \mathrm{kg})$ and etomidate $(0.3 \mathrm{mg} / \mathrm{kg})$ during cardiac catheterization in children with congenital cardiac shunts revealed no hemodynamic changes in the group with a right-to-left shunt. In cases of left-to-right shunt, there was a decrease in HR, MAP, SVR and pulmonary blood flow; whereas an increase in right atrial pressure, PAP, pulmonary artery wedge pressure and systemic blood flow [5]. In a study on children undergoing cardiac surgery, sevoflurane (1 - 1.5 MAC) was shown to reduce MAP but maintain HR, SI and CI [6]. Etomidate has a safe hemodynamic profile, attributable to its lack of effect on the sympathetic nervous system and on baroreceptor function [7]. An induction dose of etomidate results in stable hemodynamics with almost no change in HR, MAP, PAP, pulmonary capillary wedge pressure, central venous pressure, SV, CI, PVR and SVR in cardiac patients [8]. Etomidate has been reported to be safe in children with CHD due to lack of clinically significant hemodynamic changes [9]. A study of etomidate showed that induction with $0.3 \mathrm{mg} / \mathrm{kg}$ produced minimal changes in hemodynamics or shunt fraction in pediatric patients with intracardiac shunt lesions [10].

$\mathrm{EV}$ is a noninvasive method of continuous CO monitoring based on measurement of thoracic electrical bioimpedance. It has been validated in neonates [12], children [13] and adults [14] [15]. In two prospective studies comparing left ventricular output by EV and echocardiography in neonates and infants, EV was as accurate as echocardiography [12] [13]. EV was found to be a reliable technique for monitoring heart function in children after cardiac surgery and was better used to monitor changes in heart function rather than calculate absolute values [16]. EV and Doppler transthoracic echocardiography were found to be interchangeable for estimating SV after cardiac surgery in infants [17]. EV emerged as a promising technique for measuring CO during catheter interventions in patients with cavo-pulmonary circulations [18]. Two conflicting studies appeared together in 2008 regarding the reliability of EV in measuring CO in infants and children with CHD undergoing cardiac catheterization. Norozi et al. reported good agreement of CO measurements obtained by EV and those derived from the direct Fick-oxygen principle [13]. On the contrary, Tomaske et al. reported that electrical velocimetry did not provide reliable CO values when compared with thermodilution technique [19].

In the present study, the baseline HR was rather high in all groups: $159 \pm 28.0 \mathrm{bpm}$ (group K), $154 \pm 26.0$ bpm (group E) and $161 \pm 14.0 \mathrm{bpm}$ (group S). This observation points towards inadequate suppression of anxiety even after premedication. The premedication dose was probably inadequate: syrup phenargan $0.5 \mathrm{mg} / \mathrm{kg}$ orally 30 minutes before induction in children weighing more than $5 \mathrm{~kg}$, wheras it was omitted altogether in children weighing less than $5 \mathrm{~kg}$. The HR decreased after induction of anesthesia in all groups: $139 \pm 20.5 \mathrm{bpm}$ (group K), $143 \pm 23.7 \mathrm{bpm}$ (group E) and $137 \pm 16.0 \mathrm{bpm}$ (group S), due to the abolition of the sympathetic drive $(P \leq 0.01)$.

The systolic, diastolic and mean BP decreased in group $S$, with the decrease in MAP from $80 \pm 16.3 \mathrm{mmHg}$ to $64 \pm 15.1 \mathrm{mmHg}$ being more than $20 \%$ of baseline, $P \leq 0.001$. This decrease can be attributed to fall in SVR \& myocardial depression. SVR was not measured in the present study as it was not feasible to insert the central venous line before induction of anesthesia in these small children. ICON values, a parameter of myocardial contractility, reduced from $119 \pm 23.2$ to $103 \pm 25.4$ after induction in group S. Whereas, it was the same in the other two groups (105 \pm 26.7 to $107 \pm 34.4$ in group $\mathrm{K}$, and $120 \pm 41.8$ to $118 \pm 37.1$ in group $\mathrm{E}, P$ insignificant).

Etomidate caused least variation in myocardial contractility as reflected by the VIC. It remained unchanged ( $27 \% \pm 12.1 \%$ to $26 \% \pm 9.4 \%$ after induction) in group $\mathrm{E}$, unlike group $\mathrm{K}(32 \% \pm 10.8 \%$ to $22 \% \pm 12.0 \%$ ) and group S ( $30 \% \pm 9.0 \%$ to $17 \% \pm 10.0 \%)$.

The reduction in SVV, $25 \% \pm 6.4 \%$ to $13 \% \pm 6.2 \%(P \leq 0.001)$ with sevoflurane is explained by the fact that the fall in SVR that occurs with sevoflurane increases the systemic blood flow in relation to the pulmonary blood flow, thus increasing the preload \& SV. The SV improved from $9 \pm 3.2 \mathrm{ml}$ to $10 \pm 3.2 \mathrm{ml}$ with sevoflurane $(P \leq 0.05)$. The diversion of blood flow from pulmonary circulation to the systemic circulation also explains the decrease in TFC values from $22 \pm 4.5$ to $21 \pm 4.6 \Omega^{-1}$ in group $\mathrm{S}$.

SI improved in all the groups: $23.2 \pm 6.37 \mathrm{ml} / \mathrm{m}^{2}$ to $26.8 \pm 6.32 \mathrm{ml} / \mathrm{m}^{2}$ in group $\mathrm{K}, 28.4 \pm 8.49 \mathrm{ml} / \mathrm{m}^{2}$ to $29.5 \pm$ $7.37 \mathrm{ml} / \mathrm{m}^{2}$ in group $\mathrm{E}$ and $27.0 \pm 4.36 \mathrm{ml} / \mathrm{m}^{2}$ to $30.4 \pm 5.6 \mathrm{ml} / \mathrm{m}^{2}$ in group $\mathrm{S}(P \leq 0.001)$. But, CI was unchanged in all the groups: $3.7 \pm 1.36 \mathrm{~L} / \mathrm{min} / \mathrm{m}^{2}$ to $3.7 \pm 1.03 \mathrm{~L} / \mathrm{min} / \mathrm{m}^{2}$ in group $\mathrm{K}, 4.3 \pm 0.91 \mathrm{~L} / \mathrm{min} / \mathrm{m}^{2}$ to $4.1 \pm 0.95$ $\mathrm{L} / \mathrm{min} / \mathrm{m}^{2}$ in group E $4.2 \pm 0.57 \mathrm{~L} / \mathrm{min} / \mathrm{m}^{2}$ to $4.0 \pm 0.70 \mathrm{~L} / \mathrm{min} / \mathrm{m}^{2}$ in group S. This occurred secondary to an in- 
crease in preload due to simultaneous fall in HR.

The systemic arterial saturation improved in all patients as the ventilation was assisted with $50 \%$ oxygen: $79 \% \pm 16.8 \%$ to $85 \% \pm 14.8 \%$ in group $\mathrm{K}, 86 \% \pm 12.7 \%$ to $91 \% \pm 11.4 \%$ in group $\mathrm{E}$ and $87 \% \pm 17.9 \%$ to $92 \%$ $\pm 16.8 \%$ in group $\mathrm{S}(P \leq 0.01)$.

The marginal increase in $\mathrm{CaO}_{2}$ value from $15 \pm 1.7 \mathrm{ml} / \mathrm{dL}$ to $16 \pm 2.1 \mathrm{ml} / \mathrm{dL}(P \leq 0.01)$ in group E reflected a reduction in myocardial oxygen demand secondary to its cardiostable actions. $\mathrm{DO}_{2}$ (product of arterial oxygen content and CO) was unchanged in all patients as there was no significant change in CO.

To summarize, etomidate caused the least hemodynamic perturbations in the present series of patients. On the other hand, sevoflurane caused the widest fluctuations in hemodynamics. Ketamine caused hemodynamic effects intermediate between etomidate and sevoflurane.

\section{Limitations of the Study}

The study sample did not include the entire spectrum of CHD as the majority of children had cyanotic CHD (70\%) with increased pulmonary blood flow (83.3\%). Inclusion of older children and those with acyanotic CHD, reduced pulmonary blood flow conditions and obstructive lesions would have provided a comprehensive overview of the hemodynamic effects of the anesthetic induction drugs in the different subgroups of CHD. Moreover, inclusion of thiopentone and propofol as the other induction agents would have truly completed the study.

\section{Conclusion}

Etomidate appeared to provide the most stable conditions for induction of anesthesia in children undergoing cardiac surgery. Ketamine provided intermediate induction conditions for the same purpose. The present study reiterates that sevoflurane is not the ideal induction agent for children with CHD as it overloads the systemic circulation at the cost of the pulmonary circulation.

\section{Conflict of Interest}

None.

\section{References}

[1] Morray, J.P., Lynn, A.M., Stamm, S.J., Herndon, P.S., Kawabori, I. and Stevenson, J.G. (1984) Hemodynamic Effects of Ketamine in Children with Congenital Heart Disease. Anesthesia Analgesia, 63, 895-899. http://dx.doi.org/10.1213/00000539-198410000-00004

[2] Oklü, E., Bulutcu, F.S., Yalçin, Y., Ozbek, U., Cakali, E. and Bayindir, O. (2003) Which Anesthetic Agent Alters the Hemodynamic Status during Pediatric Catheterization? Comparison of Propofol versus Ketamine. Journal of Cardiothoracic and Vascular Anesthesia, 7, 686-690. http://dx.doi.org/10.1053/j.jvca.2003.09.009

[3] Berman Jr., W., Fripp, R.R., Rubler, M. and Alderete, L. (1990) Hemodynamic Effects of Ketamine in Children Undergoing Cardiac Catheterization. Pediatric Cardiology, 11, 72-76. http://dx.doi.org/10.1007/BF02239565

[4] Sungur Ulke, Z., Kartal, U., Orhan Sungur, M., Camci, E. and Tugrul, M. (2008) Comparison of Sevoflurane and Ketamine for Anesthetic Induction in Children with Congenital Heart Disease. Pediatric Anesthesia, 18, 715-721. http://dx.doi.org/10.1111/j.1460-9592.2008.02637.x

[5] Malik, M., Malik, V., Chauhan, S., Dhawan, N. and Kiran, U. (2011) Ketamine-Etomidate for Children Undergoing Cardiac Catheterization. Asian Cardiovascular and Thoracic Annals, 19, 143-148. http://dx.doi.org/10.1177/0218492311402132

[6] Rivenes, S.M., Lewin, M.B., Stayer, S.A., Bent, S.T., Schoenig, H.M., McKenzie, E.D., Fraser, C.D. and Andropoulos, D.B. (2001) Cardiovascular Effects of Sevoflurane, Isoflurane, Halothane, and Fentanyl-Midazolam in Children with Congenital Heart Disease: An Echocardiographic Study of Myocardial Contractility and Hemodynamics. Anesthesiology, 94, 223-229. http://dx.doi.org/10.1097/00000542-200102000-00010

[7] Ebert, T.J., Muzi, M., Berens, R., Goff, D. and Kampine, J.P. (1992) Sympathetic Responses to Induction of Anesthesia in Humans with Propofol or Etomidate. Anesthesiology, 76, 725-733. http://dx.doi.org/10.1097/00000542-199205000-00010

[8] Reves, J.G., Glass, P.S.A., Lubarsky, D.A., McEvoy, M.D. and Martinez-Ruiz, R. (2009) Intravenous Anesthetics. In: Miller, R.D., Ed., Miller's Anesthesia, 7th Edition, Elsevier Churchill Livingstone, Philadelphia.

[9] Sarkar, M., Laussen, P.C., Zurakowski, D., Shukla, A., Kussman, B. and Odegard, K.C. (2005) Hemodynamic Responses 
to Etomidate on Induction of Anesthesia in Pediatric Patients. Anesthesia Analgesia, 10, 645-650. http://dx.doi.org/10.1213/01.ane.0000166764.99863.b4

[10] Dhawan, N., Chauhan, S., Kothari, S.S., Kiran, U., Das, S. and Makhija, N. (2010) Hemodynamic Responses to Etomidate in Pediatric Patients with Congenital Cardiac Shunt Lesions. Journal of Cardiothoracic and Vascular Anesthesia, 24, 802-807. http://dx.doi.org/10.1053/j.jvca.2010.02.005

[11] Tibby, S.M., Hatherill, M., Marsh, M.J., Morrison, G., Anderson, D. and Murdoch, I.A. (1997) Clinical Validation of Cardiac Output Measurements Using Femoral Artery Thermodilution with Direct Fick Technique in Ventilated Children and Infants. Intensive Care Medicine, 23, 987-991. http://dx.doi.org/10.1007/s001340050443

[12] Noori, S., Drabu, B., Soleymani, S. and Seri, I. (2012) Continuous Non-Invasive Cardiac Output Measurements in the Neonate by Electrical Velocimetry: A Comparison with Echocardiography. Archives of Disease in Childhood-Fetal and Neonatal Edition, 97, F340-F343. http://dx.doi.org/10.1136/fetalneonatal-2011-301090

[13] Norozi, K., Beck, C., Osthaus, W.A., Wille, I., Wessel, A. and Bertram, H. (2008) Electrical Velocimetry for Measuring Cardiac Output in Children with Congenital Heart Disease. British Journal of Anaesthesia, 100, 88-94. http://dx.doi.org/10.1093/bja/aem320

[14] Zoremba, N., Bickenbach, J., Krauss, B., Rossaint, R., Kuhlen, R. and Schälte, G. (2007) Comparison of Electrical Velocimetry and Thermodilution Techniques for the Measurement of Cardiac Output. Acta Anaesthesiologica Scandinavica, 51, 1314-1319. http://dx.doi.org/10.1111/j.1399-6576.2007.01445.x

[15] Schmidt, C., Theilmeier, G., Van Aken, H., Korsmeier, P., Wirtz, S.P., Berendes, E., Hoffmeier, A. and Meissner, A. (2005) Comparison of Electrical Velocimetry and Transoesophageal Doppler Echocardiography for Measuring Stroke Volume and Cardiac Output. British Journal of Anaesthesia, 95, 603-610. http://dx.doi.org/10.1093/bja/aei224

[16] Schubert, S., Schmitz, T., Weiss, M., Nagdyman, N., Huebler, M., Alexi-Meskishvili, V., Berger, F. and Stiller, B. (2008) Continuous, Non-Invasive Techniques to Determine Cardiac Output in Children after Cardiac Surgery: Evaluation of Transesophageal Doppler and Electric Velocimetry. Journal of Clinical Monitoring and Computing, 22, 299307. http://dx.doi.org/10.1007/s10877-008-9133-0

[17] Grollmuss, O., Demontoux, S., Capderou, A., Serraf, A. and Belli, E. (2012) Electrical Velocimetry as a Tool for Measuring Cardiac Output in Small Infants after Heart Surgery. Intensive Care Medicine, 38, 1032-1039. http://dx.doi.org/10.1007/s00134-012-2530-3

[18] Noonan, P.M., Viswanathan, S., Chambers, A. and Stumper, O. (2014) Non-Invasive Cardiac Output Monitoring during Catheter Interventions in Patients with Cavopulmonary Circulations. Cardiology in the Young, 24, 417-421. http://dx.doi.org/10.1017/S1047951113000486

[19] Tomaske, M., Knirsch, W., Kretschmar, O., Woitzek, K., Balmer, C., Schmitz, A., Bauersfeld, U. and Weiss, M. (2008) Cardiac Output Measurement in Children: Comparison of Aesculon ${ }^{\circledR}$ Cardiac Output Monitor and Thermodilution. British Journal of Anaesthesia, 100, 517-520. http://dx.doi.org/10.1093/bja/aen024 
Scientific Research Publishing (SCIRP) is one of the largest Open Access journal publishers. It is currently publishing more than 200 open access, online, peer-reviewed journals covering a wide range of academic disciplines. SCIRP serves the worldwide academic communities and contributes to the progress and application of science with its publication.

Other selected journals from SCIRP are listed as below. Submit your manuscript to us via either submit@scirp.org or Online Submission Portal.
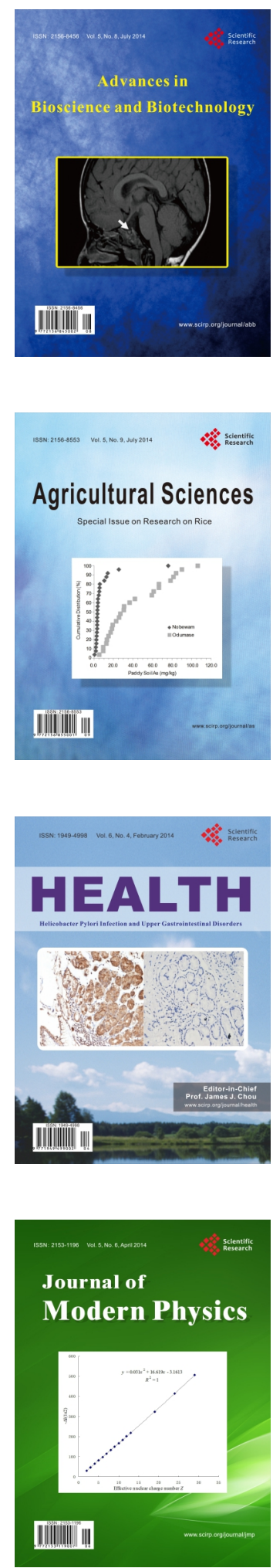
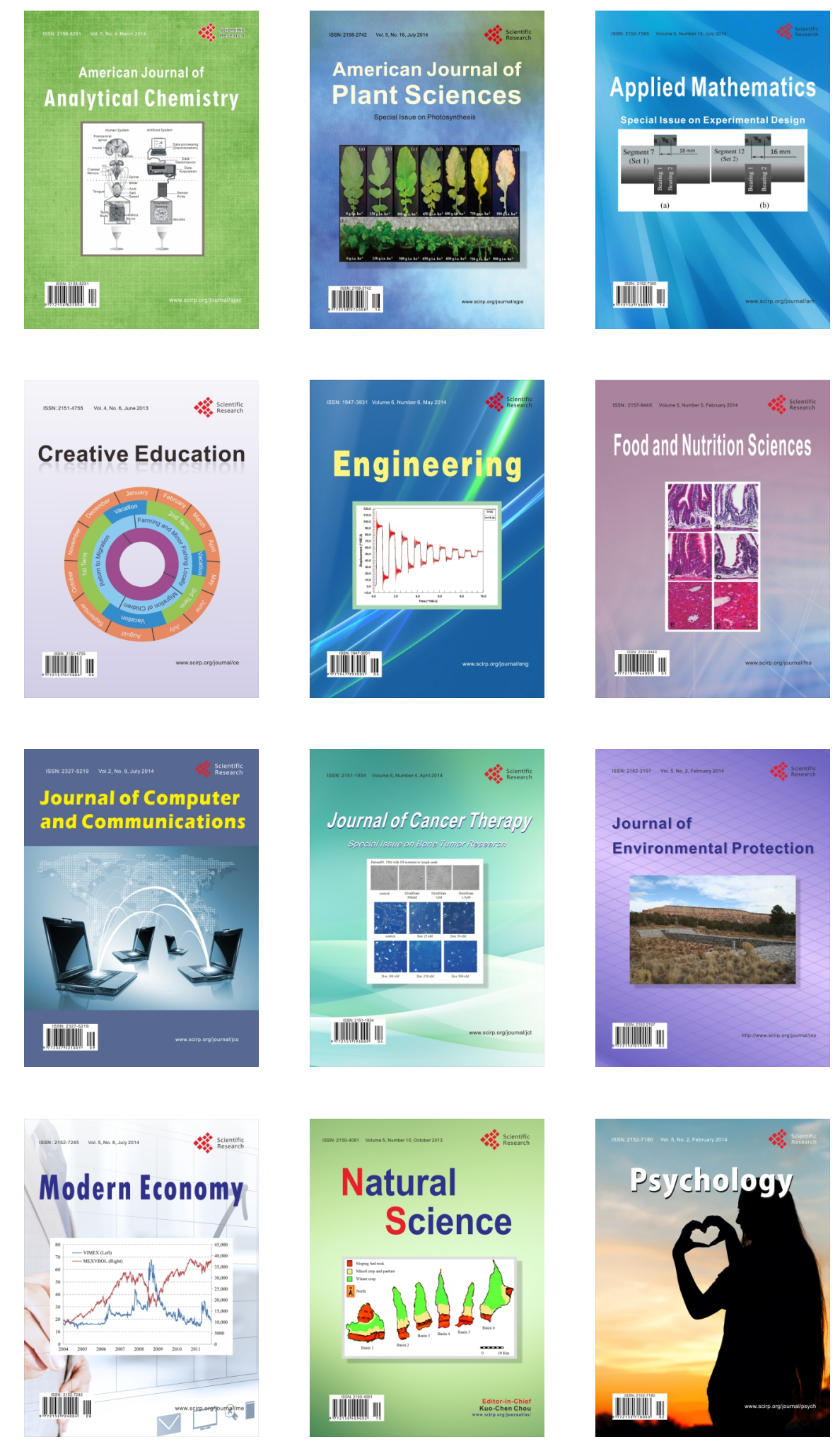